Article

\title{
Immunization with Bovine Serum Albumin (BSA) in Oil-Adjuvant Elicits IgM Antibody Response in Chinese Soft-Shelled Turtle (Pelodiscus Sinensis)
}

\author{
Cheng $\mathrm{Xu}{ }^{1,2}{ }^{2}$ Jiehao $\mathrm{Xu}^{1}{ }^{1}, \mathrm{Yu}_{\text {Chen }}{ }^{1}$, Øystein Evensen ${ }^{2}{ }^{(}$, , Hetron Mweemba Munang'andu ${ }^{2, *(1)}$ \\ and Guoying Qian ${ }^{1, *}$ \\ 1 Zhejiang Provincial Top Key Discipline of Biological Engineering, Zhejiang Wanli University, \\ Ningbo 315100, China; cheng.xu@nmbu.no (C.X.); xujiehao@zwu.edu.cn (J.X.); \\ yuchen_20@hotmail.com (Y.C.) \\ 2 Department of Paraclinical Sciences, Faculty of Veterinary Medicine, Norwegian University of Life Sciences, \\ P.O. Box 369, 0102 Oslo, Norway; oystein.evensen@nmbu.no \\ * Correspondence: hetroney.mweemba.munangandu@nmbu.no (H.M.M.); qiangy@zwu.edu.cn (G.Q.)
}

Received: 5 May 2020; Accepted: 27 May 2020; Published: 29 May 2020

\begin{abstract}
Immunoassays are among the frontline methods used for disease diagnosis and surveillance. Despite this, there are no immunoassays developed for the Chinese soft-shelled turtle (Pelodiscus sinensis), which has expanded into large scale commercial production in several Asian countries. One of the critical factors delaying the development of immunoassays is the lack of characterized soft-shelled turtle immunoglobulins. Herein, we used mass spectrometry together with the ProtQuest software to identify the soft-shelled turtle IgM heavy chain in serum, which again was used to produce a polyclonal anti-turtle-IgM in rabbits. Thereafter, the polyclonal anti-turtle-IgM was used as a secondary antibody in an indirect ELISA to evaluate antibody responses of soft-shelled turtles injected with the bovine serum albumin (BSA) model antigen. Our findings show that only turtle immunized with a water-in-oil BSA plus ISA 763A VG adjuvant (SEPPIC, France) emulsion had antibodies detected at 42 days post vaccination (dpv) while turtles injected with phosphate buffered saline (PBS) only as well as turtle injected with BSA dissolved in PBS had no significant antibody levels detected in serum throughout the study period. In summary, our findings show that rabbit polyclonal anti-turtle-IgM produced can be used in ELISA to measure serum antibody responses in immunized soft-shelled turtles. Future studies should explore its application in other immunoassays needed for the disease diagnosis and vaccine development for soft-shelled turtles.
\end{abstract}

Keywords: IgM; ELISA; immunoassay; soft-shelled turtle; immunoglobulin

\section{Introduction}

The Chinese soft-shelled turtle (Pelodiscus sinensis), formerly known as Trionyx sinensis, is widely cultured in China, Japan and Vietnam and more recently it has expanded to Korea, Malaysia, Singapore, Thailand, and Philippines [1]. Outside Asia it has been introduced in Brazil, Hawaii and Spain [2]. Its production has increased exponentially from about 5000 tons in 1994 to more than 300,000 tons in 2016 because of its high reproductive potential, pharmaceutical value, wide consumer acceptance and high demand as food for human consumption [3]. Expansion has been hampered from increasing disease problems. Bacterial species identified to cause diseases in soft-shelled turtles include Aeromonas hydrophila, A. sobria, A. veronii, Citrobacter freundii, Morganella morganii, Edwardsiella tarda and Pseudomonas aeruginosa while pathogenic fungi include Paecilomyces lilacinus, Aphanomyces sinensis and Saprolegnia spp. [4-9]. Viruses identified to cause diseases in soft shelled turtles include the Soft-shelled turtle iridovirus (STIV) [10], Trionyx sinensis hemorrhagic syndrome virus (TSHSV) [11] and turtle 
systemic septicemia spherical virus (TSSSV) [12]. To elucidate the prevalence of these pathogens, there is need to develop rapid diagnostic tools for mass surveillance.

The pace at which diagnostic tools are being developed is slower than the rate at which novel pathogens infecting the soft-shelled turtle are being discovered. There is a general lack of immunoassays required for the diagnosis of pathogens causing diseases in the soft-shelled turtle. Immunoassays are analytical assays that rely on binding between an antigen and antibody, and there are three Ig isotypes found in turtles namely $\operatorname{IgM}, \operatorname{IgD}$ and $\operatorname{IgY}[13]$. In the Chinese soft-shelled turtle, the cDNA sequence of the Ig joining $(\mathrm{J})$ chain has been cloned and characterized in which the deduced amino acid sequence has a high homology with previously reported turtle J chain $(80.7 \%)$ and of chicken $(71.3 \%)$. Significant upregulation of the J-chain transcripts quantified by RT-PCR were observed in spleen, kidney and blood of turtles vaccinated against $A$. hydrophila pointing to the importance of the $\mathrm{J}$ chain to immunization [14]. In another study, Xu et al. detected IgM, IgD and IgY mRNA in the Chinese soft-shelled turtle using qRT-PCR of which the detected IgM and IgY constant domains are similar with other vertebrate species [15]. Yet, these studies only identified the different Ig and J chain mRNA transcripts, but the proteins involved have not been characterized. The lack of characterized immunoglobulins from soft-shelled turtle has likely delayed the development of immunoassay for diagnosis of pathogens infecting the Chinese soft-shelled turtle and assessment of immune responses post infection or immunization.

The objective of the present study was to isolate and characterize the Chinese soft-shelled turtle IgM heavy chain using mass spectrophotometry followed by immunization of rabbits to raise a polyclonal anti-turtle IgM antibody. In addition, we aimed to use the developed polyclonal anti-turtle IgM antibody in an ELISA to test antibody responses in soft-shelled turtle immunized with the bovine serum albumin (BSA) as the model antigen. Ultimately, a polyclonal anti-turtle IgM antibody is then used in immunoassays for disease diagnosis and for use in evaluating antibody responses to vaccination.

\section{Material and Methods}

\subsection{Animals}

Healthy Chinese soft-shelled turtle (Pelodiscus sinensis) weighing $60 \mathrm{~g}$ on average were purchased from a Chinese soft-shelled turtle farm in Zhejiang Province, China in June 2019 and were put to acclimatize for 2 weeks at $25^{\circ} \mathrm{C}$ in freshwater in tanks before starting the experiments. They were fed daily with commercial diet (Foshan Haihuang, China) and maintained in freshwater at $25^{\circ} \mathrm{C}$ in tanks, where water was changed weekly during the acclimatization and experimental period. No attempt was made to separate the sexes. All animal experiments were carried out following the guidelines approved by the Institutional Animal Care and Use Committee at Zhejiang Wanli University in China (Ethic approval code 0520001).

\subsection{Isolation of Soft-Shelled Turtle IgM}

Ten Chinese soft-shelled turtles were anesthetized with tricaine methane-sulfonate (MS-222) (Sigma-Aldrich) and euthanatized. Blood was collected, and serum was separated from blood by centrifuging at $2500 \mathrm{rpm}$ for $15 \mathrm{~min}$. Serum was pooled from 10 turtles for IgM isolation giving a total volume of approximately $10 \mathrm{ml}$. Briefly, the same volume of saturated solution of ammonium sulphate $\left(\mathrm{NH}_{2} \mathrm{SO}_{4}\right)\left(4.1 \mathrm{M}\right.$ at $\left.25^{\circ} \mathrm{C}\right)$ was added to the pooled serum for antibody precipitation. The precipitate was resuspended in phosphate buffered saline (PBS) and dialyzed in PBS for $36 \mathrm{~h}$, and PBS was changed every $6 \mathrm{~h}$. The sample after dialysis was centrifuged at $4500 \mathrm{rpm}$ for $20 \mathrm{~min}$, and the supernatant was subjected to a second round of $\mathrm{NH}_{2} \mathrm{SO}_{4}$ precipitation and dialysis process before the isolated antibodies were analyzed by SDS-PAGE. 


\subsection{SDS-PAGE and Mass Spectrometry Analysis}

After IgM isolation, the proteins were separated by $12 \%$ SDS-PAGE gel under reduction conditions of which the electrophoretic run was performed at $200 \mathrm{~V}$ for $90 \mathrm{~min}$. Coomassie brilliant blue R250 (Sigma-Aldrich, St. Louis, MO, USA) was used to visualize the protein bands in the polyacrylamide gel electrophoresis (PAGE). Thereafter, the protein bands above $70 \mathrm{kDa}$ were excised from the polyacrylamide gel and subjected to in-gel tryptic digestion followed by liquid chromatography electrospray ionization mass spectrometry (LC-ESI-MS) analysis. Briefly, the digested protein samples were analyzed by a high-pressure liquid chromatography (HPLC) system (Agilent, Palo Alto, CA, USA), followed by mass spectrometry MS using a linear ion trap mass spectrometer (LTQ, Thermo, San Diego, CA, USA). The mass spectrometric data were used to search against the UniProt protein database with ProtTech's ProtQuest (Philadelphia, PA, USA) software suite.

\subsection{Production of Rabbit Anti-Turtle IgM Polyclonal Antibodies}

After identification of the protein bands by mass spectrometry, the band containing the IgM protein was excised and sent to HuaAn Biotechnology Co., Ltd. (Hangzhou, China) for immunization of rabbits to produce the polyclonal anti-turtle IgM antibody. Briefly, one healthy New Zealand white rabbit, weighing $2.5 \mathrm{~kg}$, was primed with $0.5 \mathrm{mg}$ IgM protein formulated in FCA and boosted 3 times with $0.25 \mathrm{mg}$ IgM protein formulated in FIA at 2-week intervals. Serum was collected 2 weeks after final immunization, and the rabbit polyclonal anti-IgM antibodies were characterized by Western blot (WB) analysis.

\subsection{Model Antigen, Vaccine Formulation and Immunization}

The bovine serum albumin (BSA) used as a model antigen was purchased from Sangon Biotech Co., Ltd. (Shanghai, China) and dissolved in PBS at the concentration of $0.5 \mathrm{mg} / \mathrm{mL}$ and kept frozen at $-20^{\circ} \mathrm{C}$ until use. The water-in-oil (W/O) emulsions containing the BSA model antigen was prepared by mixing $70 \%$ adjuvant Montanide ISA 763A VG (Seppic, Paris, France) $(\mathrm{w} / \mathrm{w})$ with $30 \%$ aqueous antigen $(\mathrm{w} / \mathrm{w})$ according to manufacturer's guidelines (Seppic, Paris, France). The final BSA concentration in the (W/O) formulation was $0.5 \mathrm{mg} / \mathrm{mL}$. Thereafter, 30 Chinese soft-shelled turtles were injected intraperitoneally with $0.2 \mathrm{~mL}$ (100 $\mu \mathrm{g} /$ turtle) of BSA dissolved in PBS (BSA/PBS-Group), and kept in 3 separate tanks maintained at $25^{\circ} \mathrm{C}$. Another 30 Chinese soft-shelled turtles were injected intraperitoneally with $0.2 \mathrm{~mL}$ (100 $\mu \mathrm{g}$ BSA/turtle) of the BSA water-in-oil emulsion (w/o) (BSA/Adjuvant-Group) and kept in 3 separate tanks maintained at $25^{\circ} \mathrm{C}$. Another 24 Chinese soft-shelled turtles were injected intraperitoneally (i/p) with $0.2 \mathrm{~mL}$ PBS (PBS-Group) and served as non-vaccinated controls. Eight individuals were sampled at day 0 (prior to vaccination) and served as reference. At 14, 28, and 42 days post-vaccination (dpv), 8-10 soft-shelled turtles from the BSA/PBS and BSA/adjuvant groups were used for blood collection (Figure 2) while from the PBS-group 8 turtles were collected at 14, 28, and $42 \mathrm{dpv}$ for blood collection. All turtles used for sample collection were anesthetized using MS-222 and euthanatized, blood was drawn, and serum was separated by centrifuging at $2500 \mathrm{rpm}$ for $15 \mathrm{~min}$ and stored at $-20^{\circ} \mathrm{C}$ until antibody analysis by ELISA.

\subsection{Chinese Soft-Shelled Turtle Antibody Analysis by Indirect ELISA}

For turtle antibody analysis by ELISA, 96-flat bottom micro-titer plates (Nunc Maxisorb, Roskilde, Denmark) were coated with $100 \mu \mathrm{L} 20 \mu \mathrm{g} / \mathrm{mL}$ BSA diluted in coating buffer $(0.05 \mathrm{M}$ carbonate-bicarbonate buffer, $\mathrm{pH}$ 9.6) and incubated at $4{ }^{\circ} \mathrm{C}$ overnight. Thereafter, the plates were washed three times with TBST $(0.02 \mathrm{M}$ Tris- $\mathrm{HCl}, 0.9 \% \mathrm{NaCl}, 0.05 \%$ Tween $20, \mathrm{pH} 7.6)$ and blocked with $300 \mu \mathrm{L} 5 \%$ dry milk in TBST for $2 \mathrm{~h}$ at room temperature. This was followed by adding $100 \mu \mathrm{L}$ sera diluted 1:50 with 1\% dry milk in TBST in duplicates to the wells and incubation for $1 \mathrm{~h}$. After washing the plates five times using TBST, $100 \mu \mathrm{L}$ rabbit anti-turtle IgM diluted 1:400 was added to the wells and incubated for $1 \mathrm{~h}$. Thereafter, plates were washed five times followed by adding horseradish peroxidase 
(HRP) conjugated goat anti-rabbit Ig (Sangon Biotech Co., Ltd., Shanghai, China) diluted 1:2000 to each well and the plates were incubated for $1 \mathrm{~h}$. After the final wash, substrate tetramethylbenzidine (TMB) was added to each well. After color development within $15 \mathrm{~min}$, the reaction was stopped by adding $50 \mu \mathrm{L}$ of $1 \mathrm{M} \mathrm{H}_{2} \mathrm{SO}_{4}$ and the optical density (OD) was measured at $450 \mathrm{~nm}$ wavelength using a Microplate spectrophotometer reader (Hangzhou Allsheng Instruments, Hangzhou, China).

\subsection{Statistical Analysis}

All statistical analyses of ELISA results were performed using GraphPad Prism version 5.00 for Windows (GraphPad Software, San Diego, CA, USA). Comparisons of antibody responses between different immunization groups was done using a Kruskal Wallis test and Stata15 for analysis. Differences were considered statistically significant at $p<0.05$ (Confidence limits 95\%).

\section{Results}

\subsection{Characterization of Soft-Shelled Turtle IgM}

Figure 1 (lane A) shows SDS-PAGE analysis of the isolated proteins including the IgM heavy chain from soft-shelled turtle serum. The expected $70 \mathrm{kDa}$ plus protein band containing the IgM heavy chain was characterized by mass spectrometry analysis. The different proteins identified using the ProtTech's ProtQuest software by blasting in the UniProt protein database is shown in Table 1, where molecular weight (MW), number of unique peptides identified for each protein and relative abundance of each protein identified are shown. The major constituents detected include serotransferrin (TF), inter-alpha-trypsin inhibitor heavy chain H3 (ITIH3), alpha-2-macroglobulin $(\alpha 2 \mathrm{M})$-like protein, immunoglobulin $\mathrm{M}(\mathrm{IgM})$ heavy chain constant region, serum albumin (sAlb) and transferrin receptor protein 1 (TFRC). Note that the largest proportion of the protein band detected was TF $(71.6 \%)$ followed by the IgM heavy chain constant region $(7.8 \%)$, ITIH3 (4.1\%), sAlb (3.4\%), $\alpha 2 \mathrm{M}(1.8 \%)$ and TFRC $(1.3 \%)$ accounting for approximately $90.0 \%$ of the total isolated proteins above $70 \mathrm{kDa}$ detected from the soft-shelled turtle serum. The isolated turtle IgM heavy chain including constant and variable region, with expected molecular weight of $70 \mathrm{kDa}$ plus is shown by western blot (WB) using the anti-turtle IgM raised in rabbit. Note that while WB analysis showed that the IgM heavy chain with a constant and variable region had a molecular weight of $70 \mathrm{kDa}$ plus (Figure 1, lane B), Table 1 shows that the IgM heavy chain constant region without variable region had a molecular weight estimated to be $56.9 \mathrm{kDa}$. This is mainly because the IgM reference sequence detected on UniProt did not have the variable region sequences, but only had the heavy chain constant region and hence the molecular weight detected by mass spectrometry had a lower MW of $56.9 \mathrm{kDa}$ that excludes the variable region.

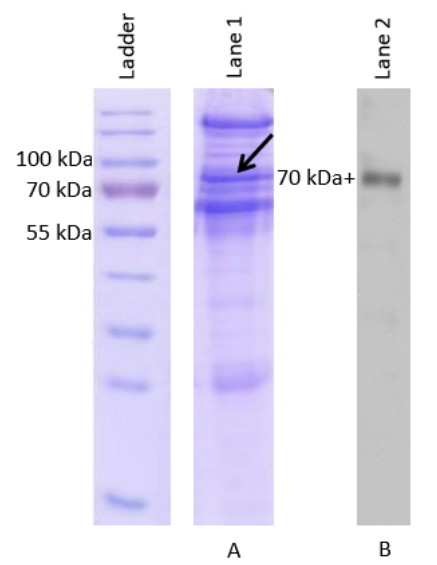

Figure 1. SDS-PAGE analysis of isolated Chinese soft-shelled turtle immunoglobulin (A) followed by Western blot (B) using anti-turtle IgM antibody raised in rabbit. The expected molecular weight of soft-shelled turtle IgM heavy chain is $70 \mathrm{kDa}$ plus as indicated by the arrow in the figure. 
Table 1. Mass spectrometry results of protein bands $\geq 70 \mathrm{kDa}$ excised from the gel electrophoresis.

\begin{tabular}{|c|c|c|c|c|c|c|c|}
\hline Hits & Protein Name & Abbr & $\begin{array}{c}\text { GeneBank } \\
\text { Acc. no. }\end{array}$ & $\begin{array}{c}\text { Molecular } \\
\text { Weight (kDa) }\end{array}$ & $\begin{array}{c}\text { Number of } \\
\text { Unique Peptides }\end{array}$ & $\begin{array}{c}\text { Relative } \\
\text { Abundance }\end{array}$ & Probability \\
\hline 1 & Serotransferrin & $\mathrm{TF}$ & XP_014429958 & 81.5 & 164 & $71.6 \%$ & $99.0 \%$ \\
\hline 2 & $\begin{array}{l}\text { Inter-alpha-trypsin inhibitor } \\
\text { heavy chain } \mathrm{H} 3\end{array}$ & ITIH3 & XP_006127649 & 100.7 & 62 & $4.1 \%$ & $99.0 \%$ \\
\hline 3 & Alpha-2-macroglobulin-like & $\alpha 2 \mathrm{M}$ & XP_014425635 & 151.8 & 36 & $1.8 \%$ & $99.0 \%$ \\
\hline 4 & $\begin{array}{l}\text { Immunoglobulin } \mathrm{M} \text { heavy } \\
\text { chain constant region }\end{array}$ & $\operatorname{IgM}$ & ACU45376 & 56.9 & 35 & $7.8 \%$ & $99.0 \%$ \\
\hline 5 & Serum albumin & sAlb & XP_006125464 & 71.0 & 28 & $3.4 \%$ & $99.0 \%$ \\
\hline 6 & Transferrin receptor protein 1 & TFRC & XP_006112414 & 84.3 & 20 & $1.3 \%$ & $99.0 \%$ \\
\hline 7 & Complement C5 & C5 & XP_006120838 & 189.1 & 11 & $0.2 \%$ & $99.0 \%$ \\
\hline 8 & Alpha-fetoprotein & AFP & XP_006125463 & 69.5 & 9 & $0.8 \%$ & $99.0 \%$ \\
\hline 9 & Complement C3 & $\mathrm{C} 3$ & XP_006124830 & 186.3 & 5 & $0.1 \%$ & $99.0 \%$ \\
\hline 10 & Kininogen-2-like & KNG2 & XP_006138593 & 87.3 & 4 & $0.3 \%$ & $99.0 \%$ \\
\hline
\end{tabular}

\subsection{Detection of Antibodies to BSA Model Antigen by ELISA}

Figure 2 shows a summary of ELISA data of antibody levels from turtles immunized with the BSA model antigen in which the rabbit polyclonal anti-turtle IgM produced in this study was used as a secondary antibody. The mean OD-levels detected before vaccination at $0 \mathrm{dpv}$ from the unvaccinated turtles was $\mathrm{OD}_{450}=0.238$ (standard error $=0.012, n=8$ ), being not significantly different from OD-levels detected at $14 \mathrm{dpv}$ in the PBS $\left(\mathrm{OD}_{450}=0.24, \mathrm{SE}=0.010, n=8\right), \mathrm{BSA}-\mathrm{PBS}\left(\mathrm{OD}_{450}=0.246, \mathrm{SE}=0.008\right.$, $n=8)$ and $\mathrm{BSA}$-adjuvanted $\left(\mathrm{OD}_{450}=0.231, \mathrm{SE}=0.009, n=8\right)$ groups indicating that there were no specific antibodies detected in response to immunization in any of the groups at $14 \mathrm{dpv}$. Similarly, there was no significant increase in OD-levels detected in the PBS $\left(\mathrm{OD}_{450}=0.252, \mathrm{SE}=0.008, n=6\right)$, BSA-PBS $\left(\mathrm{OD}_{450}=0.336, \mathrm{SE}=0.046, n=8, \mathrm{p}=0.37\right)$ and BSA-adjuvanted $\left(\mathrm{OD}_{450}=0.377, \mathrm{SE}=0.10\right.$, $n=9, \mathrm{p}=0.21$ ) groups at $28 \mathrm{dpv}$. In contrast, antibody levels detected in the BSA-adjuvant group at $42 \mathrm{dpv}\left(\mathrm{OD}_{450}=0.580, \mathrm{SE}=0.12, n=9\right)$ were significantly higher $(\mathrm{p}=0.029)$ than the PBS group $\left(\mathrm{OD}_{450}=0.197, \mathrm{SE}=0.007, n=8\right)$ and significantly higher $(\mathrm{p}=0.0268)$ than the BSA-PBS group $\left(\mathrm{OD}_{450}=0.247, \mathrm{SE}=0.017, n=8\right)$.
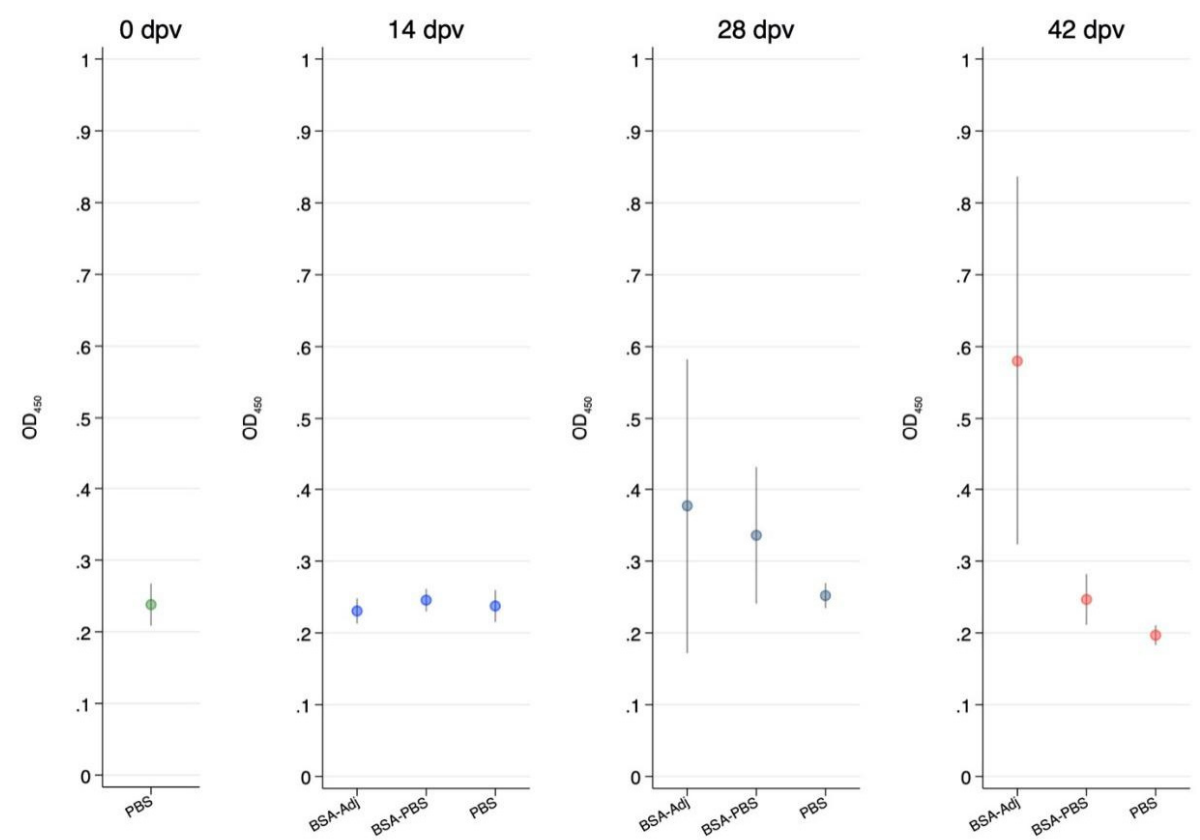

Figure 2. Serum anti-IgM antibody response of Chinese soft-shelled turtles at 0, 14, 28 and 42 days post vaccination (dpv) for phosphate buffered saline (PBS), bovine serum albumin (BSA)/PBS and BSA/adjuvant groups. Average and $95 \%$ confidence limits are shown for each group at each time post vaccination. 


\section{Discussion}

In this study, we have identified the soft-shelled turtle IgM heavy chain protein by mass spectrometry and excised it to produce a rabbit polyclonal anti-IgM antibody for use in ELISA. To the best of our knowledge, this is the first report on production of the rabbit anti-soft-shelled turtle IgM and its use to measure antibody responses by ELISA. A previous study by Xu et al. [15] detected the soft-shelled turtle IgM mRNA in blood, kidney and spleen immunized with an inactivated A. hydrophila vaccine using qRT-PCR. The major limitation with qRT-PCR detection methods is that they do not quantify the specific protein expressed by the host, and will not always reflect the magnitude of the host response to antigen stimulation. Further, antibodies are widely used as a gold standard to measure host response to vaccination in efficacy trials and they are also used as a diagnostic measure of post exposure to infection [16,17].

Adjuvants are immune potentiators known to increase the level and duration of antibody responses. In the present study, the BSA-adjuvanted group had high IgM levels at $42 \mathrm{dpv}$ and significantly lower in the non-adjuvanted BSA-PBS group. Time of immune induction used in the present study was chosen from a previous study [15] that had peak IgM mRNA levels at $35 \mathrm{dpv}$ followed by a sharp decline to insignificantly low levels at $42 \mathrm{dpv}$ in soft-shelled turtles immunized with an inactivated A. hydrophila vaccine. Here we found by ELISA that serum antibody levels in the adjuvanted BSA group were highest at $42 \mathrm{dpv}$ suggesting that antibody levels were still on an increase at this time. The kinetics of humoral responses show that a latent phase occurs between the time when B- and T-cells first contact a novel antigen to proliferation and differentiation to produce antibodies. In general, this latent phase is shorter in birds being three to five days [18] while in mammals it lasts about one to two weeks [19]. Zimmerman et al. [20] showed that in reptiles the latent phase lasts about six to eight weeks when IgM levels begin to increase to reach peak levels being in line with our observations that IgM levels were higher at $42 \mathrm{dpv}$ than at earlier sampling time points. Another important factor shown to influence the kinetics of antibody responses in reptiles is seasonal changes in immune function mainly influenced by temperature changes [21]. As pointed out by Zimmerman [21], the immune response of ectotherm is often depressed after prolonged exposure to cold. Grey [22] showed that painted turtles (Chrysemus pincta) injected with $25 \mathrm{mg}$ BSA reared at 22 to $25^{\circ} \mathrm{C}$ had antibodies detected at six weeks post vaccination in the group injected with BSA plus adjuvant, which is in line with our findings that the soft-shelled turtle cultured at $25^{\circ} \mathrm{C}$ in the present study developed antibodies in the BSA-adjuvant group being the same temperature range $\left(22\right.$ to $\left.25^{\circ} \mathrm{C}\right)$ and duration of six weeks post vaccination for antibodies increase in both Grey's [22] and the present study. Nonetheless, future studies should seek to determine the peak and duration of antibody responses using post vaccination samples collected over a longer period after vaccination than what was used in the present study. Differences between adjuvanted and non-adjuvanted vaccine preparations should also be studied in more detail.

The use of mass spectrometry for identification and characterization of antibodies has been described by several scientists [23,24], and as pointed out by Ladwig et al. [24], when using mass spectrometry to identify and characterize antibodies, the heavy chain variable region is the target and its uniqueness is compared with existing antibody repertoires. Similarly, in the present study we used the ProtTech's ProtQuest software followed by blasting in the UniProt protein database to show that the $70 \mathrm{kDa}$ plus protein excised from the polyacrylamide gel contained the IgM heavy chain peptides that match with the existing soft-shelled turtle IgM heavy chain constant region sequences. The neutralizing ability of soft-shelled turtle antibodies against bacteria has previously been tested using the serum agglutination test by Cheng-zhu et al. [25], and they found that serum from soft-shelled turtles immunized with $A$. hydrophila lipopolysaccharide (LPS) agglutinated live bacteria and blocked its replication in vitro [25]. Suffice to point out that various serum constituents contribute to the agglutination of pathogens and these include complement, TF, $\alpha 2 \mathrm{M}, \mathrm{sAlb}$ and various Ig isotypes [26-28] being similar with several proteins detected by mass spectrometry from the soft-shelled turtle serum in the present study. Therefore, it is likely that these proteins could have contributed to the agglutination of bacteria reported in the previous studies [25]. Here we focused 
on determining the antibody levels of serum IgM after immunization by ELISA excluding several other serum agglutinants. In summary, our findings show that the rabbit polyclonal anti-turtle-IgM made in this study can reliably be used to measure antibody responses induced in soft-shelled turtles. Future studies should seek to optimize the ELISA developed herein and to explore the application of the rabbit polyclonal anti-turtle-IgM in other immunoassays for the diagnosis of various infectious diseases and vaccine development for the Chinese soft-shelled turtle.

\section{Conclusions}

In this study we have used mass spectrometry to identity the soft-shelled turtle IgM heavy chain that we used to produce a polyclonal anti-turtle IgM in rabbit. Using the polyclonal anti-turtle IgM produced herein as a secondary antibody in an indirect ELISA, we have shown that soft-shelled turtle injected with BSA-adjuvant produced antibodies that increased by $42 \mathrm{dpv}$ being in line with a previous study done by Grey [22] who detected antibodies in painted turtles (Chrysemus pincta) injected with BSA-adjuvant reared at 22 to $25^{\circ} \mathrm{C}$ after 6 weeks post immunization. Put together, these findings suggest that turtles exposed to the same temperature range respond to antigen stimulation in a similar pattern resulting in antibody production at same rate. Overall, we have shown that the rabbit polyclonal anti-turtle antibody produced herein can reliably be used in ELISA to measure antibodies produced in response to immunization in soft-shelled turtle. We advocate that future studies should validate the ELISA developed herein for use in diagnosis of infectious diseases and vaccine development.

Author Contributions: Conceptualization, C.X., J.X., G.Q. and H.M.M.; data curation, C.X., J.X. and Y.C.; formal analysis, Y.C., J.X. and H.M.M.; funding acquisition, C.X.; investigation, H.M.M.; methodology, C.X. and Ø.E.; project administration, C.X.; resources, G.Q.; supervision, C.X., G.Q. and H.M.M.; writing一original draft, C.X., Ø.E. and H.M.M.; writing-review and editing, C.X., Ø.E. and H.M.M. All authors have read and agreed to the published version of the manuscript.

Funding: This study was funded by Zhejiang Provincial Top Key Discipline of Biological Engineering (ZS2017012) and Basic Scientific Research Foundation of Zhejiang Provincial Universities, and partly by the BIOAQUA project no. 283566, funded by the Research Council of Norway.

Conflicts of Interest: Authors declare no conflict of interest.

\section{References}

1. Ullah, S.; Yang, P.; Zhang, L.; Zhang, Q.; Liu, Y.; Chen, W.; Waqas, Y.; Le, Y.; Chen, B.; Chen, Q. Identification and characterization of telocytes in the uterus of the oviduct in the Chinese soft-shelled turtle, P elodiscus sinensis: TEM evidence. J. Cell. Mol. Med. 2014, 18, 2385-2392. [CrossRef]

2. Kraus, F. Alien Reptiles and Amphibians: A Scientific Compendium and Analysis; Springer Science \& Business Media: Honolulu, HI, USA, 2008; Volume 4.

3. Food and Agriculture Organization of the United Nations. Cultured Aquatic Species Information Programme, Fisheries and Aquaculture Department, Trionyx sinensis (Weigmann, 1834). 2018. Available online: http: //www.fao.org/fishery/culturedspecies/Trionyx_sinensis/en (accessed on 20 May 2020).

4. Chen, J.; Zhu, N.; Kong, L.; Bei, Y.; Zheng, T.; Ding, X.; He, Z. First case of soft shell disease in Chinese soft-shelled turtle (Trionyx sinens) associated with Aeromonas sobria-A. veronii complex. Aquaculture 2013, 406, 62-67. [CrossRef]

5. Chung, T.; Yi, S.; Kim, B.; Kim, W.; Shin, G. Identification and antibiotic resistance profiling of bacterial isolates from septicaemic soft-shelled turtles (Pelodiscus sinensis). Veterinární Med. 2017, 62, 169-177. [CrossRef]

6. Keyu, X.; Xiaoqing, W.; Daorong, Z.; Shuqiu, L.; Wucheng, J. Isolation and identifcation of the soft-shelled turtle furonculosis pathogen. J. Hunan Agric. Coll. 1991, 3, 500-505.

7. Lakshminarayanan, R.; Vivekanandan, S.; Samy, R.P.; Banerjee, Y.; Chi-Jin, E.O.; Teo, K.W.; Jois, S.D.; Kini, R.M.; Valiyaveettil, S. Structure, self-assembly, and dual role of a $\beta$-defensin-like peptide from the Chinese soft-shelled turtle eggshell matrix. J. Am. Chem. Soc. 2008, 130, 4660-4668.

8. Li, X.L.; Zhang, C.L.; Fang, W.H.; Lin, F.C. White-spot disease of Chinese soft-shelled turtles (Trionyx sinens) caused by Paecilomyces lilacinus. J. Zhejiang Univ. Sci. 2008, 9, 578-581. 
9. Takuma, D.; Wada, S.; Kurata, O.; Hatai, K.; Sano, A. Aphanomyces sinensis sp. nov., isolated from juvenile soft-shelled turtle, Pelodiscus sinensis, in Japan. Mycoscience 2011, 52, 119-131. [CrossRef]

10. Huang, Y.; Huang, X.; Liu, H.; Gong, J.; Ouyang, Z.; Cui, H.; Cao, J.; Zhao, Y.; Wang, X.; Jiang, Y. Complete sequence determination of a novel reptile iridovirus isolated from soft-shelled turtle and evolutionary analysis of Iridoviridae. BMC Genom. 2009, 10, 224. [CrossRef]

11. Liu, L.; Cao, Z.; Lin, F.; Ye, X.; Lu, S.; Lyv, S. The histopathological characteristics caused by Trionyx sinensis hemorrhagic syndrome virus (TSHSV) and comparative proteomic analysis of liver tissue in TSHSV-Infected Chinese soft-shelled turtles (Pelodiscus sinensis). Intervirology 2017, 60, 19-27.

12. Chen, M.; Li, D.; Fang, J.; Zhang, L.; Gu, Y.; Liu, L.; Zhang, G. Apolipoprotein mediates soft-shelled turtle systemic septicemia spherical virus (STSSSV) infection. Aquaculture 2017, 473, 501-507.

13. Magadán-Mompó, S.; Sánchez-Espinel, C.; Gambón-Deza, F. Immunoglobulin genes of the turtles. Immunogenetics 2013, 65, 227-237. [CrossRef]

14. Xu, Z.; Chang, M.; Qi, Z.; Huang, B.; Nie, P. Immunoglobulin joining (J) chain and its expression in the Chinese soft-shelled turtle (Pelodiscus sinensis). Vet. Immunol. Immunopathol. 2009, 131, 268-272. [CrossRef]

15. Xu, Z.; Wang, G. IgM, IgD and IgY and their expression pattern in the Chinese soft-shelled turtle Pelodiscus sinensis. Mol. Immunol. 2009, 46, 2124-2132.

16. Plotkin, S.A. Correlates of protection induced by vaccination. Clin. Vaccine Immunol. 2010, 17, $1055-1065$. [CrossRef]

17. Munang'andu, H.M.; Evensen, Ø. Correlates of protective immunity for fish vaccines. Fish Shellfish. Immunol. 2019, 85, 132-140.

18. Snoeijs, T.; Van Den Steen, E.; Eens, M.; Pinxten, R. Kinetics of primary antibody responses to sheep red blood cells in birds: A literature review and new data from great tits and European starlings. Anim. Biol. 2007, 57, 79-95. [CrossRef]

19. Coico, R.; Sunshine, G. Immunology: A Short Course; John Wiley \& Sons: Hoboken, NJ, USA, 2015.

20. Zimmerman, L.; Vogel, L.; Bowden, R.J. Understanding the vertebrate immune system: Insights from the reptilian perspective. J. Exp. Biol. 2010, 213, 661-671. [CrossRef]

21. Zimmerman, L.M. Advances in Comparative Immunology; Springer: Berlin/Heidelberg, Germany, 2018; pp. 751-772.

22. Grey, H.M. Phylogeny of the immune response: Studies on some physical chemical and serologic characteristics of antibody produced in the turtle. J. Immunol. 1963, 91, 819-825.

23. Schoenherr, R.M.; Saul, R.G.; Whiteaker, J.R.; Yan, P.; Whiteley, G.R.; Paulovich, A.G. Anti-peptide monoclonal antibodies generated for immuno-multiple reaction monitoring-mass spectrometry assays have a high probability of supporting Western blot and ELISA. Mol. Cell. Proteom. 2015, 14, 382-398.

24. Ladwig, P.M.; Barnidge, D.R.; Willrich, M.A. Mass spectrometry approaches for identification and quantitation of therapeutic monoclonal antibodies in the clinical laboratory. Clin. Vaccine Immunol. 2017, 24, e00545-e00616.

25. Jia, Y.d.; Wang, C.-z.; Chen, C.-f. Immune Response of Crude Lipopolysaccharide of Aeromonas hydrophila to Soft-shelled Turtle, Pelodiscus sinensis. J. Huazhong Agric. Univ. 2007, 2, 228-232.

26. Zhang, D.; Xu, D.-H.; Beck, B. Analysis of agglutinants elicited by antiserum of channel catfish immunized with extracellular proteins of virulent Aeromonas hydrophila. Fish Shellfish. Immunol. 2019, 86, 223-229. [CrossRef]

27. Berends, E.T.; Kuipers, A.; Ravesloot, M.M.; Urbanus, R.T.; Rooijakkers, S.H. Bacteria under stress by complement and coagulation. FEMS Microbiol. Rev. 2014, 38, 1146-1171. [CrossRef]

28. Elkhatib, W.F.; Hair, P.S.; Nyalwidhe, J.O.; Cunnion, K.M. New potential role of serum apolipoprotein E mediated by its binding to clumping factor A during Staphylococcus aureus invasive infections to humans. J. Med. Microbiol. 2015, 64, 335. [CrossRef]

(C) 2020 by the authors. Licensee MDPI, Basel, Switzerland. This article is an open access article distributed under the terms and conditions of the Creative Commons Attribution (CC BY) license (http://creativecommons.org/licenses/by/4.0/). 